\title{
On the Nature of Cytoplasmic Inclusions of Nocardia rubra
}

\author{
By J. N. ADAMS and N. M. McCLUNG \\ Department of Bacteriology, University of Georgia, Athens, Georgia, U.S.A.
}

(Received 14, August 1961)

\begin{abstract}
SUMMARY
A cytological investigation of cell walls, lipid granules, metachromatic granules and chromatinic bodies of Nocardia rubra revealed that each of these structures existed as separable entities. Multicellularity was not observed, as indicated by the lack of septa in non-fragmenting organisms, but lipid inclusions were frequently found in close association with cell walls. Metachromatic granules were separable from lipid inclusions and were found to be homologous with electron opaque granules. No evidence for the origin of metachromatic granules as cytoplasmic condensations upon cell septa was found. Acid hydrolysis or ribonuclease treatment revealed Giemsa-staining chromatinic structures which were removed by deoxyribonuclease digestion. Metachromatic granules were not removed by ribonuclease, deoxyribonuclease hydrolysis or a combination of both, but these granules were removed by acid hydrolysis.
\end{abstract}

\section{INTRODUCTION}

In recent years several investigators have studied the cytology of members of the genus Nocardia (Bisset \& Moore, 1949; McClung, 1950; Morris, 1951; Webb, Clark \& Chance, 1954; Webb \& Clark, 1957; Hagedorn, 1959 $a, b$ ). Although their studies have been extensive, frequently the findings of these authors have been conflicting. The present investigations were initiated to augment knowledge of this group and to attempt to consolidate the different hypotheses which have been advanced about the cytology of the genus.

\section{METHODS}

Nocardia rubra received as Proactinomyces ruber (Casabó) Bald, from the Centraalbureau voor Schimmel cultures) Bacillus megaterium, and B. subtilis from the stock culture collection of the University of Georgia, were used in these studies. The organisms were routinely maintained on Difco nutrient agar slopes, and transferred at appropriate intervals prior to the manipulations which will be described below.

Cell-wall staining. The cell-wall staining techniques of Robinow (1945), Welshimer \& Robinow (1949) and that of Webb (1954) as used by Adams \& McClung (1960) were compared. Both conventional and heat-fixed impression smears of Nocardia rubra and Bacillus megaterium were made on microscope slides, and stained according to the above methods.

Chromatin staining. Several chromatin-staining methods, involving many modifications of the techniques as originally described, were examined in order to compare the results of other workers who studied the genus Nocardia. The crystal violet nuclear staining method developed by Chance (1952) and used by Webb, Clark \& 
Chance (1954) and by Webb \& Clark (1957) for Nocardia corallina, was tested with heat-fixed impressions and those fixed over the vapours of $2 \%(\mathrm{w} / \mathrm{v}) \mathrm{OsO}_{4}$, of $N$. rubra and Bacillus subtilis. Modifications of Chance's method were attempted in which Hucker's crystal violet (Society of American Bacteriologists, 1957), 0.5\% $(\mathrm{w} / \mathrm{v})$ aqueous crystal violet or $\mathbf{0 . 5} \%(\mathrm{w} / \mathrm{v})$ aqueous Azure A was substituted for the $1 \%(\mathrm{w} / \mathrm{v})$ aqueous crystal violet used in the unmodified technique.

The staining method devised by Smith (1950), eliminating formaldehyde mordanting, in which $0.3 \%(\mathrm{w} / \mathrm{v})$ aqueous basic fuchsin served as the chromatin stain was used in preliminary experiments with osmium-fixed impression smears of Nocardia rubra. The effects of different $\mathrm{pH}$ values of staining reagent were studied by preparing $0 \cdot 3 \%(\mathrm{w} / \mathrm{v})$ basic fuchsin in $0 \cdot 1 \mathrm{~N}-\mathrm{Na}_{2} \mathrm{HPO}_{4}+\mathrm{KH}_{2} \mathrm{PO}_{4}$ at pH 5.5, 5.9, $6 \cdot 8$ and $7 \cdot 9$ and substituting these dye solutions for the aqueous solution originally recommended. Periods of hydrolysis in $\mathrm{N}-\mathrm{HCl}$ at $60^{\circ}$ were from 2 to $10 \mathrm{~min}$. and the effects of these variations were observed after staining with $0.3 \%$ $(w / v)$ aqueous basic fuchsin.

The following modification of Robinow's (1945) Giemsa chromatin staining technique was used as a basis for study. Impression smears of Nocardia rubra, fixed through the agar with osmium tetroxide vapours, were prepared, the organisms treated for $10 \mathrm{~min}$. in $\mathrm{N}-\mathrm{HCl}$ at $60^{\circ}$, washed in tap water, then distilled water. The smear was then strined in a solution of 1 part Giemsa stock solution to 10 parts tap water for $\mathbf{3 0}$ min. at room temperature, mounted in distilled water under a coverslip, sealed with paraffin and examined.

Modifications of Robinow's technique were attempted and determinations of optimum staining times were carried out by varying the periods of staining at room temperatures from 5 to $30 \mathrm{~min}$. Sinears which were stained and mounted under a coverslip in distilled water were compared to those which were stained and observed directly. The effects of treatment with $\mathrm{HCl}$ for 2 to $10 \mathrm{~min}$. were determined as described above. The effects of ribonuclease digestion were determined according to the methods of Tulasne \& Vendrely (1947): osmium-fixed impression smears were digested in situ with $0.02 \%(\mathrm{w} / \mathrm{v})$ ribonuclease in $0.1 \mathrm{~m}-\mathrm{Na}_{2} \mathrm{HPO}_{4}+\mathrm{KH}_{2} \mathrm{PO}_{4}$ $(\mathrm{pH} 7 \cdot 0)$ at $55^{\circ}$ for $15 \mathrm{~min}$. and stained in a $1 / 10$ dilution of Giemsa's stock solution in tap water for $5 \mathrm{~min}$. The preparation was then washed in distilled water, blotted, and observed directly. The effects of deoxyribonuclease were determined by digesting an osmium tetroxide-fixed preparation in $0.02 \%(\mathrm{w} / \mathrm{v})$ deoxyribonuclease dissolved in the buffer described ahove, at $55^{\circ}$ for $15 \mathrm{~min}$. These were stained and examined in the manner already described.

Metachromatic granule staining. Heat-fixed impressions of Nocardia rubra were stained for metachromatic granules with Loeffler's methylene blue (Society of American Bacteriologists, 1957) for 1.5 min. The preparation was then washed with distilled water, blotted and examined. A modification of this technique was used in which $0 \cdot 25 \%(\mathrm{w} / \mathrm{v})$ methylene blue adjusted to $\mathrm{pH} 3 \cdot 1,4 \cdot 9,7 \cdot 1$ or $8 \cdot 3$ with $0 \cdot 04 \mathrm{M}$ $\mathrm{Na}_{2} \mathrm{HPO}_{4}$ was substituted for Loefler's methylene blue. Mudd's (1953) technique was also used for the demonstration of these granules.

The effects of hydrolysis in $\mathrm{N}-\mathrm{HCl}$ at $60^{\circ}$ for $6 \mathrm{~min}$. on the appearance of metachromatic granules in Nocardia rubra were observed by staining hydrolyzed organisms with methylene blue at $\mathrm{pH} 3 \cdot 1$ or with $0.5 \%(w / v)$ aqueous Azure A substituted in the method described above. The effects of ribonuclease and deoxy- 
ribonuclease digestion on the appearance of metachromatic granules in $N$. rubra were observed by digesting organisms as already described and staining with methylene blue at $\mathrm{pH} 3 \cdot 1$.

Lipid staining. Heat-fixed impression smears of Nocardia rubra were stained according to Burdon's (1946) Sudan Black B method; this technique was modified by omitting the counterstain. The lipid-staining method of Clark \& Aldridge (1960) was also used.

The effects of lipase digestion of heat-fixed impression preparations were also studied. These experiments were conducted by subjecting Nocardia rubra to digestion with a $0.01 \%(\mathrm{w} / \mathrm{v})$ solution of lipase in $0 \cdot 1 \mathrm{M}-\mathrm{Na}_{2} \mathrm{HPO}_{4}+\mathrm{KH}_{2} \mathrm{PO}_{4}(\mathrm{pH} 7 \cdot 0)$ at room temperatures for 15 and $30 \mathrm{~min}$. periods. The preparations were then stained by the modified Burdon technique and examined for the presence of lipid inclusions.

Successive staining. Two successive staining techniques similar to those of Tronnier (1953) and Knaysi (1955 $a, b, 1959)$, were used in the present work. The first method may be more readily described as counterstaining rather than successive staining; this method for the differentiation of lipid inclusions from metachromatic granules was carried out as follows : a heat-fixed impression smear of Nocardia rubra was stained by the modified Burdon technique. A counterstain was then used by treating with Azure A to reveal metachromatic granules. After treating the smear with both staining reagents, the slide was washed in distilled water, blotted and examined. This method allowed simultaneous demonstration of lipid inclusions and metachromatic granules. A second more complex method for successive staining was done as follows : an osmium-fixed impression was prepared in the usual way and stained with one of the previously described stains (e.g. Azure A for metachromatic granules). The slide was observed under oil, representative fields located and mechanical stage settings recorded; sketches of the field under observation also aided a return to the same field. Such fields were then photographed. The immersion oil was then removed with xylene, which also partially decolorized the preparation. Further decolorization was carried out with $95 \%(\mathrm{v} / \mathrm{v})$ ethanol in water until no more colour was removed. The slide was then washed in copious quantities of water and, after drying, restained by one of the methods described above (e.g. Burdon's modified lipid-staining technique); the fields which had previously been photographed were again located. After re-examination and re-photographing, the preparation could again be decolorized, after which staining for a third or fourth time was possible. Although the sequence of staining techniques applied to a single preparation was theoretically unlimited, practical considerations led to definite sequences which had to be used. Acid hydrolysis, as used in the chromatin-staining procedures, partially destroyed cellular integrity, and consequently was limited to the last place in a successively-stained sequence. Likewise, mordanting in $10 \%(w / v)$ tannic acid for $30 \mathrm{~min}$., as used in cell-wall staining techniques, affected the staining affinity of the organism, hence cell-wall staining was usually relegated to the last or next to last position of a sequence. However, sometimes cell-wall staining had to be done first in a sequence.

Microphotography. A Bausch and Lomb Dynoptic Research Microscope equipped with a $2 \mathrm{~mm}$., N.A. $1 \cdot 30$ apochromatic objective with a $\times \mathbf{1 2 . 5}$ compensating ocular and a variable focus condenser (N.A. 1·40) was used with a Bausch and Lomb 
$35 \mathrm{~mm}$. microphotographic camera. A green filter was used to increase photographic contrast with Kodak High Contrast Copy $35 \mathrm{~mm}$. film as the negative material. Magnification at the negative plane was $\times 900$.

Electron microscopy. Nutrient agar slope cultures of Nocardia rubra were incubated for $5 \mathrm{hr}$. The organisms were removed from the slope, suspended in distilled water and a drop of suspension placed on a copper-grid supported collodion membrane. After the drop had dried the organisms on the surface of the membrane were washed with distilled water, re-dried and shadow-cast with platinum + palladium. Some preparations were treated for $2.5 \mathrm{~min}$. in $\mathrm{N}-\mathrm{HCl}$ at $60^{\circ}$ and washed three times in distilled water before placing them on the collodion membrane for observation with the RCA EMU-2 electron microscope.

\section{RESULTS}

The cell-wall staining methods of Robinow (1945), Welshimer \& Robinow (1949) and Webb (1954) were all found to be suitable for the demonstration of the cell walls of Bacillus megaterium, but only 'Webb's technique resulted in the consistent demonstration of cell walls and septa in young (Pl. 1, fig. 1) and old (Pl. 1, fig. 2) Nocardia rubra preparations. In the present investigations several methods were used to locate and differentiate metachromatic granules from other inclusions of $N$. rubra. Successive staining techniques were most fruitful in these respects. The location of septa and metachromatic granules was found to differ when a comparison was made of organisms stained for metachromatic granules with Azure A (Pl. 1, fig. 3), and decolorized and restained for cell walls (Pl. 1, fig. 4). The 'septa' seen at the arrows in Pl. 1, fig. 4, are metachromatic granules which stained bright-red and were incompletely decolorized with the xylene + ethanol treatment; in contrast, septa (Pl. 1, fig. 2) always stained a bright purple colour. In organisms successively stained for metachromatic granules and lipid inclusions (Pl. 1, figs. 5, 6) it was evident that metachromatic granules were not composed of lipids but that structures stained by these two methods could be closely associated. The counterstaining of Sudan Black B stained cells with Azure A confirmed their close, but separable, association.

Metachromatic granules, stained brightly with methylene blue at $\mathrm{pH} \mathbf{3} \cdot 1$, against a contrasting lightly-stained cytoplasm are shown in $\mathrm{Pl} .2$ fig. 9 . When using methylene blue reagent at various $\mathrm{pH}$ values, it was found that, as the $\mathrm{pH}$ value increased the cytoplasm stained more intensely, until at $\mathrm{pH} 8 \cdot 3$ ( $\mathrm{Pl}$. 2, fig. 10) metachromatic granules were undifferentiated or differentiated only slightly from the cytoplasm. Thus the $\mathrm{pH}$ value effects accounted for the poor differentiation of metachromatic granules observed when staining with Loeffler's methylene blue. The granules which stained with methylene blue at $\mathrm{pH} \mathrm{3 \cdot 1}$ were not removed by digestion with ribonuclease (Pl. 2, fig. 11) or by deoxyribonuclease (Pl. 2, fig. 12); but acid treatment removed them completely.

Electron opaque granules (Pl. 1, fig. 7) observed in young organisms were located in similar positions and were of the same form as the granules which were seen when metachromatic granules were stained in young organisms. Further evidence for the homology of electron opaque granules with metachromatic ones resulted from the removal of electron opaque granules by hydrolysis with $\mathrm{N}-\mathrm{HCl}$ for $2.5 \mathrm{~min}$. (Pl. 1, fig. 8). 
Chance's (1952), Smith's (1950) and Robinow's (1945) methods for chromatin staining and modifications of these were compared to determine the relationship, if any, of metachromatic granules to nuclear materials. Organisms stained by Chance's method, without modification are shown in Pl. 3, figs. 15, 16 and 18. Fivehr. germinating organisms of Nocardia rubra (PI. 3, fig. 15) contained single chromatinic structures in cell portions from which germ tubes originated but organisms from an $18 \mathrm{hr}$. culture (Pl. 3, fig. 16) contained chromatinic bodies throughout the filament length. Similar results were obtained when Hucker's crystal violet or $0.5 \%(w / v)$ aqueous crystal violet were used. When Azure A was substituted for crystal violet in Chance's (1952) procedure, distinct bright-red staining granules (Pl. 3, fig. 17) were distributed at some distance from each other along the filament length, suggesting that Azure A did not stain chromatinic bodies but metachromatic granules by this procedure. Evidence for homology of chromatinic bodies stained by the unmodified procedure of Chance with metachromatic granules demonstrated by means of Azure A staining can be seen in organisms stained successively for these structures in $\mathrm{Pl}$. 3, figs. 18 and 19, respectively. From these figures it is obvious that crystal violet non-differentially stained metachromatic granules which were then not distinguishable from similarly stained chromatinic structures. Additional evidence for the non-specificity of the crystal violet nuclear staining technique for chromatinic bodies of $N$. rubra is shown in the following observations. Chromatinic structures were revealed in germ tube segments of young organisms (Pl. 3, fig. 20) stained by Smith's (1950) or Robinow's (1945) techniques (Pl. 3, fig. 21). Chromatinic structures of germ tubes of germinating cells were not visible, however, in preparations stained by Chance's method (Pl. 3, fig. 15).

The modified technique of Smith (1950) was effective for the demonstration of distinct chromatinic structures in old non-germinating cells of Nocardia rubra. Chromatinic structures in organisms from cultures older than 3 days stained without appreciable differences when subjected to periods of acid treatment ranging from 2 to $7 \mathrm{~min}$. However, both the $\mathrm{pH}$ value of the staining solution and the duration of hydrolysis preceding application of the stain affected the affinity for the stain of germ-tube chromatinic structures. The affinity of the chromatinic structures of the germ tube portions of the organisms varied inversely with the time of acid treatment and with decrease of $\mathrm{pH}$ value. As the hydrolytic period increased from 2 to $10 \mathrm{~min}$. the affinity of the germ tube chromatinic bodies decreased. As the pH value changed discontinuously (see methods) from $5 \cdot 5$ to $6 \cdot 7$, their staining affinity increased; it remained constant when tested at $\mathrm{pH} 6 \cdot 7$ and $7 \cdot 5$. Optimum staining of the germ tube bodies was obtained when organisms were heated for 5 min. and stained at $\mathrm{pH} 6.7$ ( $\mathrm{Pl} .3$, fig. 20). However, as the age of the cultures increased to 15-20 hr., the staining affinity of chromatinic structures changed in relation to the duration of acid treatment; $2.5 \mathrm{~min}$. was about optimum. These findings lend further support to the observed differences between staining affinities of germ-tube chromatinic structures and chromatinic structures in mature hyphae when stained by Chance's technique (compare Pl. 3, figs. 15-20).

The method of Robinow (1945) was found to be only applicable to Nocardia rubra when osmium tetroxide-fixed impressions were observed directly. Mounting in water sealed under a coverslip decreased the definition of chromatinic structures of Giemsa-stained preparation as compared to unmounted preparations, thus con- 
firming similar observations on several organisms by Cassel (1951). Nevertheless, water mounting was found to be quite suitable for Bacillus subtilis.

The length of the periods of treatment with $\mathrm{N}-\mathrm{HCl}$ was found to affect only slightly the definition and affinity of chromatinic structures of Nocardia rubra cells for Giemsa's solution. Periods of treatment from 2 to $10 \mathrm{~min}$. were satisfactory for demonstrating these structure $\mathrm{s} ; 6 \mathrm{~min}$. was optimum. Duration of the periods of immersion of the preparations in dilute Giemsa's solution also affected the definition of chromatinic structures. We found that a staining period of $5 \mathrm{~min}$. at room temperature was optimum for N. rubra, while Robinow's (1945) original procedure was satisfactory with Bacillus subtilis.

While the acid-hydrolysis (riemsa technique is one generally accepted for the demonstration of chromatinic structures of bacteria (Robinow, 1956) conflicting reports about the nuclear elements of members of the genus Nocardia (Morris, 1951; McClung, 1950, 1955, 1956; Webb et al. 1954; Webb \& Clark, 1957; Clark \& Frady, 1957; Hagedorn, $1959 a, b)$ dictated a re-evaluation of the specificity of this method as applied to Nocardia rubra. Osmium tetroxide-fixed impression smears of this organism, stained without previous acid or other treatment with Giemsa's solution, were found to have a medium to dark-blue stained cytoplasm interspersed with bright-red stained granules. Such untreated organisms appeared much like those stained for metachromatic granules with Azure A. Treatment with ribonuclease before staining with Giemsa's solution resulted in organisms like those shown in Pl. 2, fig. 13. Although dark-blue stained chromatinic bodies became visible as a result of ribonuclease digestion, the bright-red stained metachromatic granules were not affected. Deoxyribonuclease treated organisms contained lightly staining bands such as those seen at $A$ in Pl. 2, fig. 14, but also contained bright-red staining bodies such as those seen at $B$. When treated with ribonuclease and deoxyribonuclease, the organisms stained with a mottled appearance, with no obvious separation of distinct granules other than the metachromatic granules which stained bright red. Organisms stained successively for metachromatic granules with Azure A (Pl. 3, fig. 23) and chromatinic bodies (Pl. 3, fig. 24) by Robinow's technique, offered further evidence that the metachromatic granules and chromatinic bodies were not homologous. Bright-red metachromatic granules visible after Azure A staining, as shown at the arrows in Pl. 3, fig. 23, were not observed at identical sites in Giemsastained preparations of the same organisms; see arrows in Pl. 3, fig. 24. Furthermore, bright-red granules were not visible after the application of Giemsa's solution; only chromatinic bodies which stained dark blue against very light blue cytoplasm were seen in acid-treated Giemısa-stained preparations.

Lipid inclusions in Nocardia rubra were readily observed by means of the modified Burdon technique (Pl. 1, fig. 6) but the counterstain used in the unmodified technique sometimes masked small lipid granules. Preparations stained successively for metachromatic granules and lipid inclusions (Pl. 1, figs. 5, 6) indicated that, although these two kinds of structures may be closely associated, they were separable entities. The apparent diameter of organisms stained for lipid inclusions compared with those stained for cell walls suggested that these structures were closely associated. In preparations stained by the method of Clark \& Aldridge (1960), lipid inclusions were contrasted sharply against the nigrosin background (PI. 1, fig. 6a) but when a comparison was made between nigrosin-decolorized organisms and non-decolorized 
organisms in the same field, it was evident that many lipid granules were completely or partially decolorized as a result of the action of nigrosin. Lipase digestion under the conditions used in these experiments did not affect the affinity of these granules for Sudan Black B.

\section{DISCUSSION}

As early as 1898 Lachner-Sandoval described fragmentation of actinomycetes following septation. It was later reported by Lieske (1921) that fragmentation occurred after separation of the protoplasm, without prior septation, after which individuals separated. More recently (Bisset \& Moore, 1949; McClung, 1950) the problem of the existence of septa in the actinomycetes and the genus Nocardia in particular, has been re-examined. Bisset \& Moore (1949) reported that multicellularity was a characteristic of the genus Nocardia, but McClung (1950) was unable to demonstrate septa in N.rubra by means of Dyar's (1947) cell-wall staining technique. He later observed, by phase microscopy, that septum formation preceded fragmentation of $N$. rubra (McClung, 1955). Cell walls and septa of $N$. corallina were demonstrated by Webb et al. (1954) who suggested that anomalous multicellularity of this organism, time of fragmentation, and non-septate filament length, were influenced by environmental factors such as medium composition. By ultrathin sectioning, Hagedorn $(1959 a, b)$ did not observe multicellularity of $N$. corallina, except as a result of fragmentation. Under the conditions of the present experiments, non-fragmenting organisms of $N$. rubra were not multicellular, thus confirming the reports of previous investigators and of the authors (Adams \& McClung, 1960).

Many investigators have discussed the deeply-staining granules of an unknown nature present in actinomycetes. Neukirch (1902) reported that strongly refractive granules could be stained with dilute solutions of methylene blue. Gilbert (1904), however, did not confirm the presence of such granules. Drechsler (1919) and Lieske (1921) observed in actinomycetes refractive granules which the former described as occluded wastes and the latter as nuclei. Lieske (1921) speculated whether there might be two types of methylene-blue staining granules, the first nuclear and the second, which appeared frequently at the apical tips of growing hyphae, as reserve materials such as volutin. Von Plotho (1948) was unable to demonstrate methylene-blue staining granules before acid hydrolysis in $\mathbf{5}$ day coccoids of Nocardia rubra, but McClung (1950) clearly established their presence by using different basic aniline dyes. The present studies have indicated a possible solution to the questions raised by the foregoing authors about the nature of these granules. We have shown that the manifestation of metachromatic granules with methylene blue is dependent upon the $\mathrm{pH}$ value of the solution used. Earlier workers did not indicate that the $\mathrm{pH}$ value of the staining reagent was taken into consideration and it seems likely that this factor was responsible for the conflicting results which have been previously reported.

Electron-opaque granules, designated type ' $A$ ' by McClung (1956), were observed in the present studies. Winkler (1953) who used a technique in which the same organisms were observed successively in the light-microscope and in the electronmicroscope, found that electron-opaque granules of a bacillus were homologous with the metachromatic granules. By using a similar technique, Glauert \& Brieger 
(1955) found that the electron opaque granules of Mycobacterium phlei were identical with the metachromatic granules observed by light microscopy, but were not analogous with nuclei seen when the HCl-Giemsa technique was used. Oiwa (1960) reported that the acid-fast granules and electron opaque granules of $\boldsymbol{M}$. avium appeared identical when studied by this technique. The location and hydrolyzable nature of the electron-opaque bodies of Nocardia rubra indicated that they were not nuclear in nature but similar to the electron-opaque inclusions described by the above authors and as volutin by Grula, Weaver \& Edwards (1954) in Caulobacter. Lieske (1921) suggested that some of the deeply-staining granules present in actinomycetes were the result of cytoplasmic condensations; this idea was promulgated by Bisset (1952, 1953) who suggested that septa are sites of such condensations. The present successive-staining studies have negated the plausibility of such an explanation at least for $N$, rubra. The close proximity of cell walls and electron-opaque granules in this organism was shown in electron micrographs previously published by the authors (Adams \& McClung, 1960).

The problem of the nucleus of actinomycetes has received attention through the years. Grigorakis (1931) reported amitotically dividing nuclei in Actinomyces bovis. The observations of Schaede (1939), however, were not in accord with such findings and he reported that the Feulgen technique resulted only in a diffuse uptake of the stain by the organism in question. Newcomer \& Kenknight (1939) and von Plotho (1940) reported the presence of Feulgen-positive bodies in actinomycetes. McClung (1950) was unable to demonstrate a Feulgen-positive reaction in Nocardia rubra examined by conventional techniques; but when staining was carried out at $45^{\circ}$ (McClung, 1953, unpublished data) Feulgen-positive bodies were observed. Hagedorn (1959 a) reported that Feulgen-positive bodies could be found in Nocardia corallina.

The results of workers who used techniques other than the Feulgen reaction have not been so contradictory in demonstrating the presence of nuclear materials in organisms of the genus Nocardia. With the electron microscope McClung (1950) observed two types of granules present in $N$. rubra grown on nitrogen-deficient medium. He postulated that one of these structures was nuclear in nature, but he was unable to differentiate chromatinic bodies from metachromatic granules on the basis of concurrent light microscope observations of stained organisms. However, he did find that the solubilities of certain of these granules observed in stained preparations precluded the deduction of the homology of these granules with volutin. Webb et al. (1954) observed discrete nuclei in $N$. corallina, and in further studies (Webb \& Clark, 1957) indicated that a complex developmental cycle existed, involving fragmentation and rearrangement of the nuclear apparatus of the organism. Hagedorn (1959 $a$ ) objected to certain of their interpretations and suggested that inadequacies inherent in the crystal-violet nuclear-staining technique which they used accounted for faulty conclusions. In contrast, Hagedorn $(1959 a, b)$ described amitotically-dividing spherical to ovoid nuclei which were observed in ultrathin sections of $N$. corallina. Since we have shown that the crystal-violet staining technique may non-differentially stain metachomatic granules and may not stain chromatinic bodies demonstrable by other more specific means (e.g. Smith's or Robinow's techniques) our studies tend to confirm the suggestions of Hagedorn $(1959 a, b)$. The interpretations of Webb et al. (1954), and of Webb \& Clark (1957) about ploidy changes suggested by microscopic observations with the crystal-violet 
nuclear-staining technique would, as a result of the studies of Hagedorn $(1959 a, b)$ and ourselves, appear to be somewhat uncertain. However, Morris (1951) described a complex life cycle for members of the genus Nocardia in which complex nuclear reorganizations were observed by the acid Giemsa technique. Although we have not attempted to remove inclusion bodies of $N$. rubra stained by this technique and subject them to chemical analysis, the specificity of enzyme digestion and the resultant appearance of organisms after ribonuclease and deoxyribonuclease digestion strongly suggests that they are, in fact, composed primarily of deoxyribonucleic acid. Since genetic analysis of ploidy of members of the genus Nocardia has not yet been undertaken, it would appear advisable that further work should be done to determine more fully the role of the chromatinic structures during the developmental cycles of members of the genus Nocardia.

Parts of this study were taken from a dissertation submitted to the Graduate Faculty of the University of Georgia in partial fulfilment of the requirements for the degree of Doctor of Philosophy by JNA. This investigation was supported in part by a research grant (No. E-2075) from the National Institute of Allergy and Infectious Diseases; Public Health Service.

\section{REFERENCES}

Adams, J. N. \& McClung, N. M. (1960). Morphological studies in the genus Nocardia. V. Septation in Nocardia rubra and Jensenia canicruria. J. Bact. 80, 281.

Bisset, K. A. (1952). The interpretation of appearances in the cytological staining of bacteria. Exp. Cell Res. 3, 681 .

Bisset, K. A. (1953). Bacterial cell envelopes. In Bacterial Cytology. Symp. 6th Congr. int. Microbiol. p. 9.

Bisser, K. A. \& Moone, F. W. (1949). The relationship of certain branched bacterial genera. J. gen. Microbiol. 3, 387.

Burdon, K. L. (1946). Fatty material in bacteria and fungi revealed by staining dried, fixed side preparations. J. Bact. 52, 665 .

CASSEL, W. A. (1951). A procedure for the simultaneous demonstration of the cell walls and chromatinic bodies of bacteria. J. Bact. 62, 239.

Chance, H. L. (1952). Crystal violet as a nuclear stain for Gaffkya tetragena and other bacteria. Stain Tech. 27, 253.

Clark, J. B. \& Aldridge, C. (1960). Fat bodies in Nocardia corallina. J. Bact. 79, 756.

Clark, J. B. \& Frady, J. (1957). Secondary life cycle of Nocardia corallina. J. Bact. 74, 698.

Drechsler, C. (1919). Morphology of the genus Actinomyces, I and II. Bot. Gaz. 67, 65, 147.

DYAR, M. T. (1947). A cell wall stain employing a cationic surface-active agent as a mordant. J. Bact. 53, 498.

Gilbert, A. (1904). Uber Actinomyces thermophilus und andere Actinomyceten. $Z$. Hyg. Infekt-Kr. 47, 383.

Glauert, A. M. \& Brieger, E. M. (1955). The electron-dense bodies of Mycobacterium phlei. J. gen. Microbiol. 13, 310.

Grigorakis, L. (1931). Morphologie et cytologie des actinomyces. C.R. Acad. Sci., Paris, 193, 540.

Grula, E. A., Weaver, R. H. \& Edwards, O. F. (1954). Studies on a strain of Caulobacter from water. II. Nutrition, with implications for cytology. J. Bact. 68, 201.

HAGEDORN, H. (1959a). Licht-und elektronenmikroskopische Untersuchungen an Nocardia corallina (Bergey et al. 1923). Zbl. Bakt. (Abt. 2), 112, 214. 
Hagedorn, H. (1959b). Elektronenmikroskopische Untersuchungen uber den Teilungsverlauf bei Nocardia corallina (Bergey et al. 1923). Z Zbl. Bakt. (Abt. 2), 112, 359.

KNaYsI, G. $(1955 a)$. The structure composition, and behavior of the nucleus in Bacillus cereus. J. Bact. 69, 117.

KNAYSI, G. $(1955 b)$. On the structure and nature of the endospore in strain $\mathrm{C}_{3}$ of Bacillus cereus. J. Bact. 69, 130.

KNaYSI, G. (1959). Chemical composition of the granules of Mycobacterium thamnopheos, with special reference to their biological identity and the chemical nature of volutin. J. Bact. 77, 532.

Lachner-Sandoval, V. (1898). Uter Strahlenpilze. Dissertation, Strassburg, Abstract in $\mathrm{Zbl}$. Bakt. (Abt. 2) 25, 782.

LIESKe, R. (1921). Morphologie und Biologie der Strahlenpilze. Leipzig: Gebr. Borntraeger.

McClung, N. M. (1950). Morphological studies in the genus Nocardia. II. Cytological studies. J. Bact. $59,589$.

McClung, N. M. (1955). Morphological studies in the genus Nocardia. IV. Bright phase contrast observations of living cells. Trans. Kans. Acad. Sci. 58, 50.

McClung, N. M. (1956). The cytology of Proactinomyces (Nocardia) ruber (Casabó) Baldacci as revealed by the electron microscope. Proc. First Regional Conf. Electronmicroscopy. Asia and Oceania, 81.

Morris, E. O. (1951). Observations on the life cycle of the Nocardia. J. Hyg., Camb., 49, 175.

MudD, S. (1953). The Mitochondria of Bacteria. In Bacterial Cytology. Symp. 6th Congr. int. Microbiol. p. 57.

Neukirch, H. (1902). Uber Strahlenpilze (Actinomyceten). Thesis, Strassburg. Cited after Lieske (1921).

Newcomer, E. \& Kenknight, G. (1939). Nuclei in Actinomyces. Pap. Mich. Acad. Sci. 25,85 .

Orwa, K. (1960). What part of the cell of mycobacteria is responsible for acid-fastness? Studies by means of electron and light microscopes. Jap. J. Tuberc. 8, 53.

Plotho, O. von. (1940). Die chromatische Substanze bei Actinomyceten. Arch. Mikrobiol. $11,285$.

Plotho, O. von. (1948). Untersuchungen an Proactinomyceten. Arch. Mikrobiol. 14, 12.

RoBinow, C. F. (1945). Nuclear apparatus and cell structure of rod-shaped bacteria. In Addendum to The Bacterial Cell, by R. J. Dubos, Cambridge, Mass: Harvard University Press.

Robinow, C. F. (1956). The chromatin bodies of bacteria. Bact. Rev. 20, 207.

Schaede, R. (1939). Zum Problem des Vorkommens von chromatischer Substanz bei Bacterien und Actinomyceten. Arch. Mikrobiol. 10, 473.

Sмrтн, A. G. (1950). Electron and light microscopic studies of bacterial nuclei. II. An improved staining technique for the nuclear chromatin of bacterial cells. J. Bact. 59, 575.

Society of American Bacteriologists (1957). Manual of Microbiological Methods. New York: McGraw-Hill Book Company, Inc.

Tronnier, E. A. (1953). Zur Existenz des sogenannten Karyoid-Systems bei Corynebacterium diphtheriae. Zbl. Bakt. (Abt. 1), 159, 213.

Tulasne, R. \& Vendrely, R. (1947). Demonstration of bacterial nuclei with ribonuclease. Nature, Lond. 160, 225.

WeBb, R. B. (1954). A useful bacterial cell wall stain. J. Bact. 67, 252.

Webs, R. B. \& Clark, J. B. (1957). Cytogenetic study of Nocardia corallina. J. Bact. 74, 31.

Webb, R. B., Clark, J. B. \& Chance, H. L. (1954). A cytological study of Nocardia corallina and other actinomycetes. J. Bact. 67, 498.

Welshimer, H. J. \& Robinow, C. F. (1949). The lysis of Bacillus megatherium by lysozyme. J. Bact. 57, 489.

Winkler, A. (1953). The metachromatic granula of bacteria. In Bacterial Cytology. Symp. Congr. int. Microbiol. p. 39. 


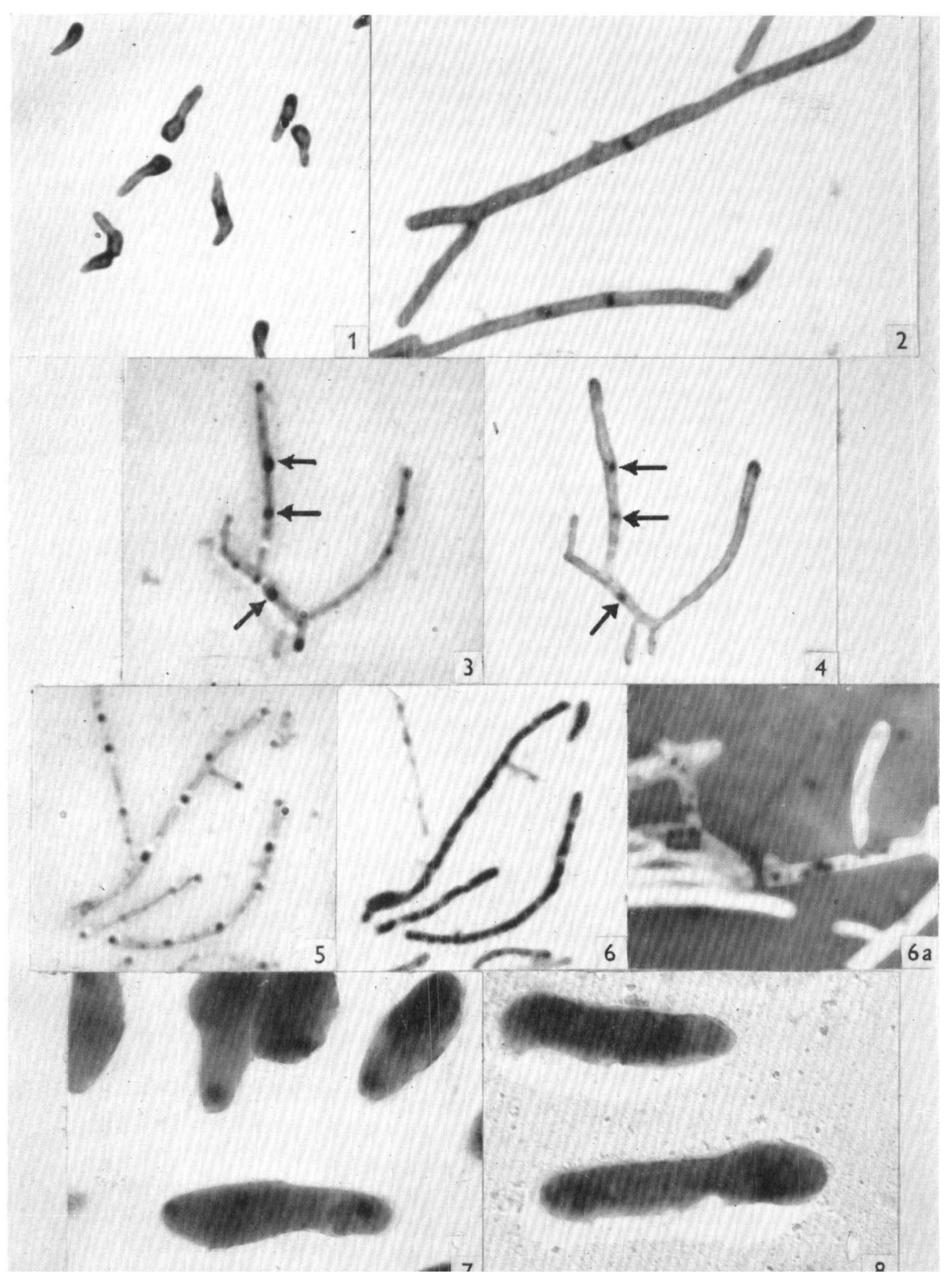


Journal of General Hicrobiology, Vol. 28, No. 2

Plate 2

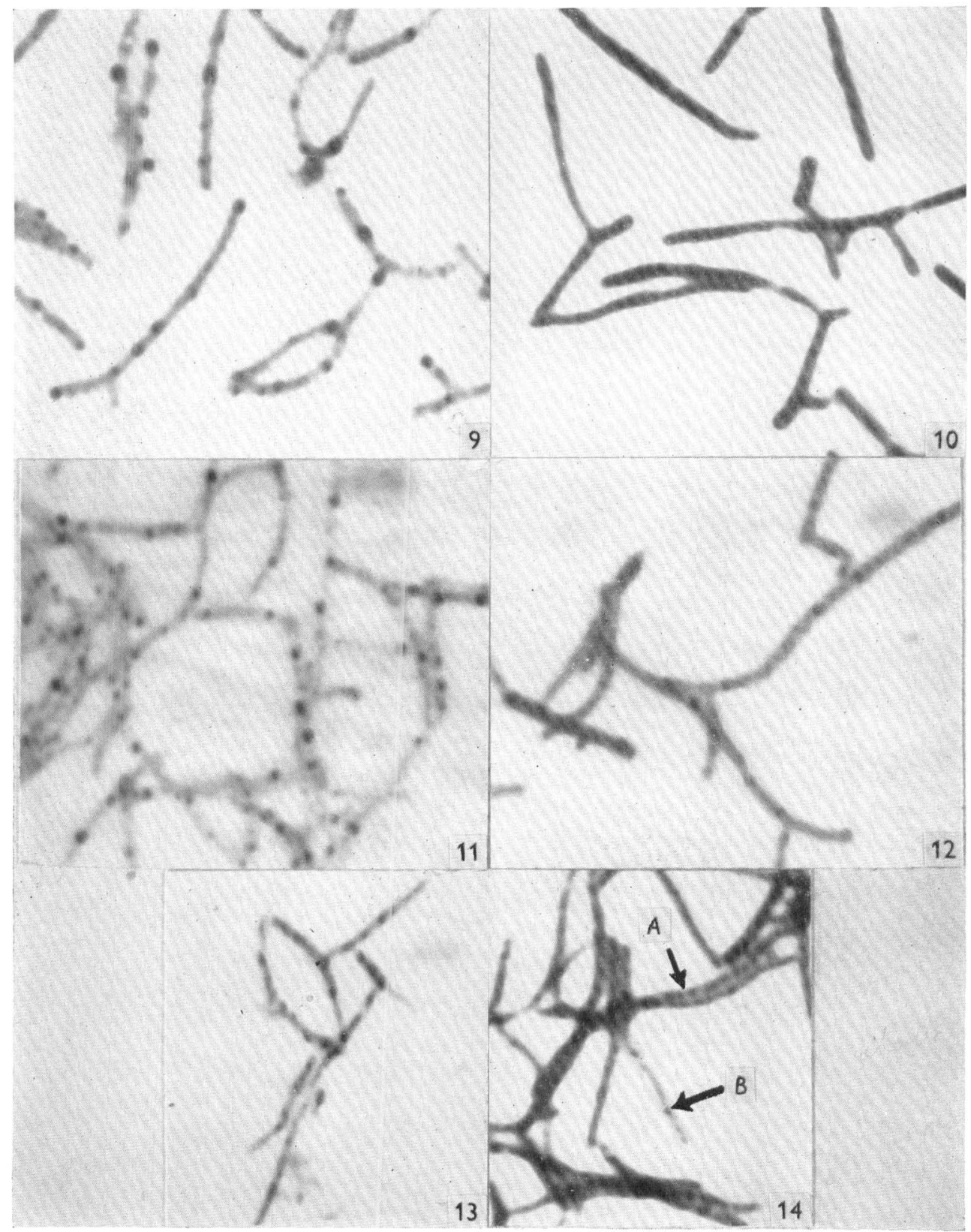

J. N. ADAMS ANI N. M. MCCLUNG 
Journal of General Microbiology, Vol. 28, No. 2

Plate 3

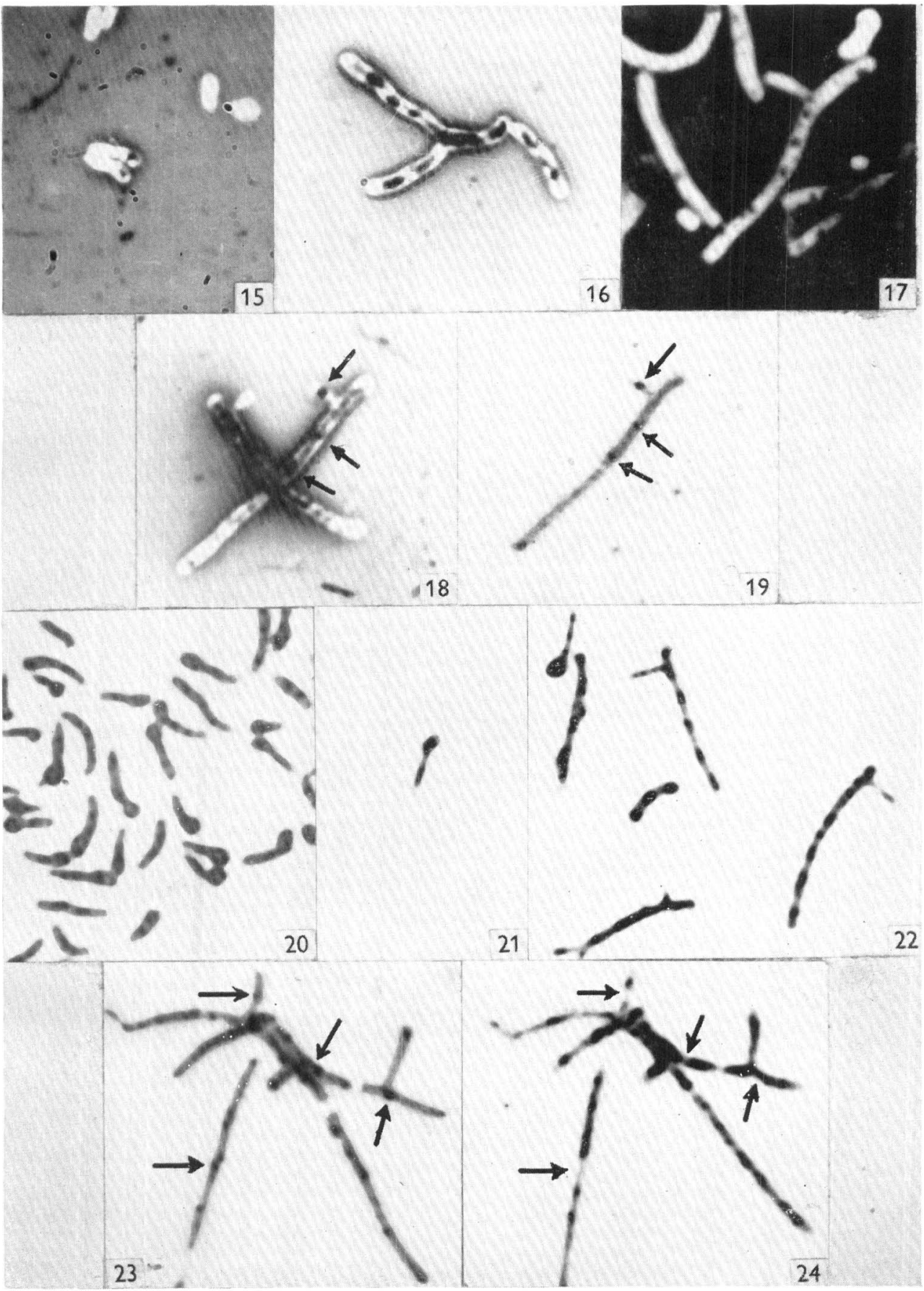

J. N. ADAMS AND N. M. MCCLUNG 


\section{EXPLANATION OF PLATES}

Figs. 1-6a, 9-24. Light micrographs of Nocardia rubra. $\times 2500$.

Figs. 7, 8. Electron micrographs of Nocardia rubra. $\times 13,300$.

\section{Plate 1}

Fig. 1. Germinating organism, $8 \mathrm{hr}$. culture. Webb's cell-wall stain.

Fig. 2. Filamentous organisms, $18 \mathrm{hr}$. culture. Webb's cell-wall stain.

Figs. 3, 4. Branching organisms, $18 \mathrm{hr}$. culture, stained successively for metachromatic granules and cell walls. Arrows indicate identical locations in each figure. Fig. 3. Azure A stain. Fig. 4. Organism shown in Fig. 3, Webb's cell-wall stain.

Figs. 5, 6. Organisms from $18 \mathrm{hr}$. culture stained successively for metachromatic granules and lipid inclusions. Fig. 5. Azure A stain. Fig. 6. Same organism as shown in Fig. 5, stained for lipid inclusions. Modified Burdon technique.

Fig. 6a. Organisms from $18 \mathrm{hr}$. culture, Clark and Aldridge lipid stain.

Fig. 7. Direct electron microscope preparation, $5 \mathrm{hr}$. culture. Shadowed with platinum + palladium.

Fig. 8. Organisms from $5 \mathrm{hr}$. culture hydrolysed with $\mathrm{N}-\mathrm{HCl}$ for $2.5 \mathrm{~min}$. before direct electronmicroscope preparation. Shadowed with platinum + palladium.

Plate 2

Figs. 9-14. Organisms from $18 \mathrm{hr}$. cultures.

Fig. 9. Stained with methylene blue $(\mathrm{pH} 3 \cdot 1)$.

Fig. 10. Stained with methylene blue (pH $8 \cdot 3)$.

Fig. 11. Organisms digested with ribonuclease, stained with methylene blue $(\mathrm{pH} 3 \cdot 1)$.

Fig. 12. Organisms digested with deoxyribonuclease, stained with methylene blue (pH $3 \cdot 1$ ).

Fig. 13. Organisms digested with ribonuclease, stained with dilute Giemsa's solution.

Fig. 14. Organisms digested with deoxyribonuclease, stained with dilute Giemsa's solution. Banding effects of digestion indicated by arrow at $A$; metachromatic granule indicated by arrow at $B$.

\section{Plate 3}

Fig. 15. Germinating organisms, from $5 \mathrm{hr}$. culture. Unmodified Chance's nuclear stain.

Fig. 16. Branching organism from $18 \mathrm{hr}$. culture. Unmodified Chance's nuclear stain.

Fig. 17. Organisms from $18 \mathrm{hr}$. culture. Chance's nuclear stain modificd by substituting Azure A for crystal violet.

Figs. 18, 19. Organisms from $18 \mathrm{hr}$. culture, stained successively for chromatinic structures and metachromatic granules. Arrows indicate identical locations in each figure. Fig. 18. Unmodified Chance's nuclear stain. Fig. 19. Same organism as shown in Fig. 18, stained for metachromatic granules, Azure A stain.

Fig. 20. Germinating organisms from $5 \mathrm{hr}$. culture. Modified Smith's basic fuchsin nuclear stain. Figs. 21, 22. Organisms stained using Robinow's acid Giemsa technique. Fig. 21. Germinating organisms from $5 \mathrm{hr}$. culture.

Fig. 22. Organisms from $18 \mathrm{hr}$. culture.

Figs. 23, 24. Organisms from $18 \mathrm{hr}$. culture stained successively for metachromatic granules and chromatinic structures. Arrows indicate identical locations in each figure. Fig. 23. Azure A stain. Fig. 24. Same organisms as shown in Fig. 23, Robinow's acid Giemsa technique. 